\title{
EKSISTENSI USHUL FIQH DALAM TAFSIR REALITAS SOSIAL DAN PERANAN PESANTREN DALAM MENJAGA DAN MENGEMBANGKANNYA
}

\author{
Ismail \\ LAIN Bukittinggi, ismailnovel68@gmail.com
}

\begin{tabular}{|c|c|c|}
\hline Diterima: 17 Februari 2019 & Direvisi :10 Mei 2019 & Diterbitkean: 30 Juni 2019 \\
\hline
\end{tabular}

\begin{abstract}
Social reality is a fact that occurs in people's lives. He is always changing and developing in accordance with the changes and developments of the times. In Islamic teachings social reality is not allowed to flow away, but rather there is a Shari'ah that regulates and directs it to something that is blessed by Allah SWT. Usul fiqh is actually quite able to provide a response to social reality. However, it is not ushul fiqh which relies on the meaning of the text. Instead, with the new ushul figh that prioritizes the side of reason or relies on the maqashid shari'ah, the meaning or purpose bebind the text. Usul figh like this which then can also give birth to contextual figh or social figh that is figh as a response to the social reality of society. The pesantren itself is actually very potential to maintain and develop this kind of science of fiqh. On the contrary, it does not struggle with traditional (classical) figh as well as traditional usbul fiqh which is only fixated on literal meanings.
\end{abstract}

Keyword:Ushul Fiqh, Social Reality, Pesantren

\begin{abstract}
Abstrak
Realitas sosial adalah fakta atau realitas sosial yang berlangsung pada kebidupan masyarakat. Ia senantiasa berubah dan berkembang mengikuti perubahan dan perkembangan masa. Dalam ajaran Islam realitas sosial tidak. dibiarkan mengalir begitu saja, melainkan ada syariat yang mengatur dan mengarabkannya kepada sesuatu yang diridhai oleh Allah SWT. Ushul figh sebenarnya cukup bisa memberikan respon terhadap realitas sosial.Hanya saja, bukan usbul figh yang bertumpu pada makna teks.Melainkan, dengan ushul figh baru yang lebih mengedepankan sisi pemikiran atau bertumpu kepada maqashid syariab, yakni makna atau tujuan yang ada di balik. teks.Ushul fiqh yang semacam ini yang kemudian juga mampu melabirkan figh kontekstual atau fiqh sosial yakni figh sebagai respon terhadap realitas sosial masyarakat.Pesantren sendiri sebenarnya sangat potensial untuke menjaga dan mengambangkan ilmu ushul figh semacam ini.Sebaliknya, tidak berkutat dengan fiqh tradisional (klasik) begitu juga usbul fiqh tradisional yang hanya terpaku kepada makna-makna literal.
\end{abstract}

Kata Kunci: Ushul Fiqh, Realitas Sosial, Pesantren.

\section{PENDAHULUAN}

Realitas sosial merupakan kenyataan atau fakta yang berlaku pada kehidupan masyarakat. Realitas sosial, senantiasa berubah dan berkembang sama dengan perubahan dan perkembangan masa. Dalam ajaran Islam realitas sosial tidak dibiarkan mengalir begitu saja, melainkan ada syariat yang mengatur dan mengarahkannya kepada sesuatu yang diridhai oleh Allah SW'T. Tata aturan yang mengatur mengenai realitas sosial ini, dalam khasanah Islam disebut figh, yakni kumpulan dari hukum-hukum yang mengatur perbuatan lahir manusia (mukallaf) yang digali atau dikeluarkan dari dalil-dalilnya yang tertentu. ${ }^{1}$

Sesuai dengan definisinya, figh ini paling tidak, mempunyai dua fungsi. Pertama, untuk mengembangkan perilaku setiap pribadi muslim berdasarkan, aqidah, syariah, dan akhlak. Kedua, bias mewujudkan suatu tatanan kehidupan sosial kemasyarakatan yang mempunyai carakter yang kuat, berkeadilan, persamaan, dan kemitraan. ${ }^{2}$

${ }^{1}$ Busyro Busyro and Saiful Amin, "Kedudukan Bak Pencuci Kaki Sebelum Masuk Dan Keluar Tempat Berwudhuk Dalam Tinjauan Fiqh Ibadah," ALHURRIY AH: Jurnal Hukum Islam (Alburriyah Journal Of Islamic Law) 3, no. 1 (June 22, 2018): 1, doi:10.30983/alhurriyah.v3i1.538. 4

${ }^{2}$ Ahmad Rafiq, Fiqh Kontekstual, dari Normatif ke Pemaknaan Sosial, (Yogyakarta: Pustaka Pelajar, 2004), 5. 
Hanya saja, menurut Zubaedi, fiqh yang karakter dasarnya bersifat responsive, sosial, kontekstual, formalistic, dan indifidualistik yang cenderung pasif. Timbulnya pemandangan semacam ini kemungkinana disebabkan oleh terbatasnya hasanah atau literature ulama figh dalam mazhab-mazhab yang ada. Kurangnya penguasaan terhadap ilmu fiqh pada akhirnya akan berdampak pada lahirnya penafsiran mazhab tertentu yang bersifat tunggal. Mereka tidak begitu responsive kepada ijtihad mazhab lain dan berbagai persoalan masyarakat sekitarnya. ${ }^{3}$ Pada sisi lain, menurut Amien Abdullah, kemunduran figh dewasa ini dikarenakan tidak ada relevansi yang signifikan mengunakan metode ilmu ushul figh untuk menyelesaikan masalah-masalah kekinian. ${ }^{4}$

Bersamaan dengan itu, pesantren, selain sebagiannya kurang begitu fokus terhadap ilmu ushul fiqh, juga memiliki kecenderungan yang kuat untuk "mendoktrinkan", untuk tidak mengatakan "mengagamakan", figh mazhab tertentu, ketimbang mengkaji secara kritis teksteks fiqh tersebut. Kurangnya kajian terhadap metodologi ushul fiqh dan tidak tepatnya pesantren memposisikan fiqh dalam perspektif keilmuan, mengakibatkanlemahnya fungsi pesantren dalam menjaga dan mengembangkan figh dan ushul fiqh tersebut.

Tulisan ini mencoba mendiskusikan tentang untutan pengembangan figh sosial, bagaimana metode ushul figh dalam menghadapi realitas sosial, serta peranan pesantren dalam menjaga dan mengembangkannya.

\section{TUNTUTAN PENGEMBANGAN USHUL FIQH}

Sejatinya Masyarakat itu bersifat dinamis, sebaliknya tidak bersifat pasif. Oleh

\footnotetext{
${ }^{3}$ Zubaedi, Membangun Fiqh yang Berorientasi Sosial: Dialektika Fiqh dengan Realitas Empirik Masyarakat, Al-Jami'ah,(Vol.44, No.2, 2006M/1427H), 437

${ }^{4}$ Amin Abdullah, Mąhab Yogja, Menggagas Paradigma Ushul Fiqh Kontemporer, (Yogjakarta: Arruz Press, 2002), 118.
}

sebab itu, dalam setiap kehidupan masyarakat kapan dan di mana pun akan selalu terjadi perubahan sosial (social change). Sebagai konsekwensi dari setiap perubahan sosial, baik cepat atau lambat, senantiasa menghendaki pembaharuan diberbagai bidang, baik dalamnya bidang hukum dan perundangundangan yang menjadi institusi penting bagi kehidupan kemasyrakatan. ${ }^{5}$

Figh sendiri pada dasarnya juga sangat dinamis. Ia berkembang sesuai dengan perkembangan zaman dan keadaan. Ibnu Qayim al-Jauziyah mengatakan, perubahan dan perbedaan fatwa, seiring dengan perubahan masa, tempat, situasi sosial, niat, serta kebiasaan atau adat yang berlaku. ${ }^{6}$ Hanya saja, setelah figh menjadi karya besar dalam bentuk kitab-kitab fiqh mengalami kemandekan. Ulama-ulama fiqh cenderung lebih memfokuskan perhatiannnya terhadap katakata atau lebih fokus memakai pandangan harfiyah, ketimbang memperhatikan spirit atau semangat dan tujuan dari kata-kata tersebut. Pada persoalan akad perkawinan dan akad jual beli misalnya, baru dianggap sah bila diucapkan dengan kalimat-kalimat tertentu. Hingga, bila terdapat orang bukan Arab yang melaksanakan akad perkawinan dengan memakai bahasanya sendiri, akadnya dianggap tidak sah kecuali menggunakan bahasa Arab. ${ }^{7}$

Ada kecenderungan ulama (terutama kalangan tekstualis) yang berpendapat bahwa memahami maksud syara' hanya dapat diketahui dari makna tersurat secara mantuq. Seperti halnya pada ayat pencurian yang hukumannya potong tangan. Maka dapat disimpulkan bahwa hukuman bagi setiap pencuri tidak ada selain potong tangan. Alasan yang dikemukakan adalah semata-mata maksud syari (Tuhan) menjelaskannya secara

${ }^{5}$ Zubaedi, Membangun Fiqh... 434

${ }^{6} \mathrm{Ibn}$ Qayyim al-Jauziyyah, I'lamal-Muwaqqi'in 'an Rabbal-'Alamin, (Beirut: Daral-Kutubal-'Ilmiyyah, 1996), Juz3, 11.

${ }^{7}$ Hasan al-Turabi, FiqibDemokratis, terj.Abdul Haris dan Zainul Am, (Bandung: Arasy, 2003), 19. 
qath'i, dikecualikan jika ada nass lain yang jelas menyebutkan adanya makna-makna lain. Sebagai konsekuensinya, mereka berpegang pada lahirnya teks tanpa memerlukan metode di luar nass. Mereka juga menolak pendekatan qiyas, istihsan dan maslahah mursalah dalam istibath hukum. Sebaliknya, mereka mengunakan takwil secara terbatas yang berasal dari Alquran maupun Hadis Nabi. Sehingga makna zabir-nya hanya dapat dita'wil dengan lafal zabir pada ayat yang lain yang memiliki keterkaitan secara makna. ${ }^{8}$

Besertaan dengan itu terdapat kesenjangan dalam fiqh yaitu bagaimana fiqh yang dipahami secara tekstual dan kaku dapat menjawab persoalan kekinian yang terus berkembang. Beberapa penyebab terjadinya kesenjangan antara fiqh secara teoritis dengan praktis. Pertama, terdapat kekaguman lebih pada imam dan guru. Kedua, bermunculan gerakan kodifikasi figh para imam. Ketiga, pemberlakuan mazhab tertentu dalam pengadilan. Kondisi di atas menyebabkan ahli figh mencukupkan diri pada usaha membuat syarh, hasyiyah dan ikhtisar karya-karya ulama terdahulu. serta merasa puas mempertahankan keilmuan dan pemikiran yang sudah dituliskan guru-guru mereka .?

Untuk bisa menuju figh sosial pertama sekali harus dilakukan adalah merubah perspektif tentang fiqh.Figh itu bukanlah teksteks suci yang mesti diabadikan.Figh hanyalah karya ulama melalui ijtihadnya pada suatu masa dan keadaan tertentu dan dapat berubah sesuai dengan perubahan zaman.Cara pandang seperti ini terhadap figh, tidaklah keliru. Ahmad Hasan mengatakan:

Tampaknya Nabi SAW memberikan ruang yang luas dalam ikhtilaf (berbeda pendapat) dengan mengemukakan pemikiran yang bersifat umum atau membenarkan dua

\footnotetext{
8Zubaedi, Membangun Fiqh..., 431

${ }^{9}$ Farouk Abu Zaid, Hukum Islam: Antara Tradisionalis dan Modernis, terj. Husein Husein Muhammad, (Jakarta:P3M, 1986), 50
}

pendapat yang berbeda dalam situasi yang sama (mushawwibah). Semenjak awal, Nabi sangat menekankan penggunaan akal (ra'yu) dan kaidah-kaidah figh dalam berbagai kondisi dan situasi. ${ }^{10}$

Begitu juga dengan Umar Bin Khatab yang pernah berbeda pendapat dengan Bilal bin Rabah tentang Ghanimah (harta rampasan perang) berupa tanah. Bilal lebih cenderung membagi-bagikan tanah masing-masing seperlima berdasarkan Alquran kepada Allah, Rasul, kerabat Rasul, anak-anak yatim, orangorang miskin dan Ibn Sabil. Sebaliknya, Umar yang lebih cenderung menilainya dari sisi kemashlahatan melalui ijtihadnya. Tampaknya Umar mengambil sikap yang berbeda dengan ayat yang diperpegangi Bilal. Umar menyerahkan tanah tersebut kepada para petani serta hasilnya diserahkan kepada negara (baitul mal). Menurut Umar apabila diserahkan kepada prajurit maka akan terjadi kecemburuan sosial dan kesenjangan ekonomi karena urusan penggarapan tanah sebaiknya ditangani oleh petani. Imam asy-Syafi'i juga pernah beralih dari pendapatnya yang pertama (qaul qadim) yang dikeluarkannya di Irak dengan pendapat baru (qaul Jadid) ketika dia telah menetap di Mesir.

Apa yang dicontohkan oleh Nabi SAW, Umar bin Khattab, dan Imam asySyafi'i di atas menunjukkan betapa fiqh itu sangat responsif terhadap kondisi sosial suatu lingkungan masyarakat. Oleh sebab itu, agar fiqh bisa responsif terhadap perubahan, maka diperlukan penyesuaian dengan perubahan konteks sosial-budaya yang ada. Khazanah ilmu figh, yang bersifat elastis memberikan kemungkinan terjadinya perubahan hukum dari tempat ke tempat dan waktu ke waktu. Pernyataan berikut akan menggambarkan: "Perubahan fatwa itu sejalan dengan perubahan waktu, tempat, kondisi sosial, niat,

${ }^{10}$ Ahmad Hasan, The Early Development of Islamic Jurisprudence, (Islamabad: Islamic Research Institute, 1970), 13. 
dan adat kebiasaan". ${ }^{11}$

Sebagai konsekwensi logis dari responsibilitas figh terhadap kondisi suatu masyarakat adalah lahirnya apa yang disebut sebagai fiqh sosial. Fiqh sosial itu sendiri adalah pembentukan kajian fiqh yang bersifat praktis ('amaly) yang diambil dari dalil syar'i diorientasikan pada persoalan sosial kemasyarakatan. Fiqh sosial bermuara pada kesalehan dalam praktek keagamaan dalam kehidupan sehari-hari. Hal ini bersumber dari suatu gagasan dan perkembangan moralitas publik (public morality) untuk mendukung universalitas Islam. ${ }^{12}$

Dalam wilayah kesalehan perseorangan, fiqh sebagai pemikiran Islam berupaya memberikan kontribusi berupa petunjuk-petunjuk praktis keagamaan (religious practical guidance), ibadah mabdab; dan masalah-masalah yang menyangkut moralitas pribadi (private morality). Sementara itu, dalam wilayah kesalehan sosial, fiqh sebagai pemikiran Islam merespons wacana kontemporer, seperti masalah-masalah sosialkeagamaan, sosial budaya, sosial ekonomi, globalisasi, iptek, lingkungan hidup, etika dan rekayasa genetika serta pluralisme agama, HAM, kekerasan social, civil society, isu-isu keadilan hukum, ekonomi, demokratisasi, bioteknologi, sekaligus merumuskan tatanannya dalam praksis sosial. ${ }^{13}$

Figh sosial sejatinya dibangun pada prinsip proporsional (non-dikotomik) dalam menghubungkan antara kewajiban/ibadah sosial dengan kewajiban/ibadah perseorangan dengan prinsip kesalehan sosial. Dari kesemuanya itu berkedudukan yang samasama penting dalam rangka mencapai derajat keIslaman yang tinggi (insan kamil). Sesuai

${ }^{11} \mathrm{Ibn}$ Qayyim al-Jauziyyah, I'lamal-Muwaqqi in 'an Rabbal-Alamin,11.

${ }^{12} \mathrm{PP}$ Muhammadiyah,"Manhaj Pengembangan Pemikiran Islam", http://www.geocities.com/tarjikh/Manhaj_tarjih/opera sionalisasi.htm, diakses pada26 Agustus 2018 ${ }^{13}$ Ibid. dengan maksud ayat Surat Ali 'Imran ayat 112. Secara realitas, ibadah sosial yang nilai lebih bermanfaat akan didahulukan pengamalannya daripada ibadah perseorangan yang bernilai kecil manfaatnya berdampak kepada masyarakat. Terkait dengan hal ini, alSuyuti mengatakan (yang artinya; "ibadah yang bermanfaat untuk orang banyak lebih utama daripada ibadah yang bermanfaat untuk diri sendir". Pemahaman yang bisa ditarik dari ungkapan ini adalah fardu kifayah (kewajiban kolektif) lebih diutamakan daripada fardu 'ayn (kewajiban perseorangan) karena terhubung langsung dalam meminimalisis kesulitan yang dialami masyarakat, khususnya umat Islam.

Al-Syatibi dalam metode maqasid-nya berkomentar agar umat Islam perlu menjaga secara tetap melaksanakan kewajiban perseorangan dan kewajiban bersama (kolektif). Menurutnya, kewajiban kifa'iyyah yang bertentangan dengan kewajiban ayniyyah merupakan kewajiban bersama masyarakat yang harus dilakukan secara bersama-sama dengan suatu sistem tertentu. Landasan dari kewajiban kifa'iyyah dari sisi kepentingannya termasuk dalam prinsip maqasid al-Shari'ah. Seiring dengan itu apabila kewajiban kifa'iyyah yang beragam itu terlaksana, maka sejatinya akan mengikut kewajiban ayniyyah terlaksananya pula. Inilah yang menjadikan tujuan dari kewajiban kifa'iyyah untuk merealisasikan kebaikan secara umum (almaslahat al-'ammah). ${ }^{14}$

Berdasarkan pendapat di atas, gagasan fiqh sosial yang dibangun merupakan suatu kesadaran bahwa umat Islam semestinya mengkolabolasikan pola keberagamaan yang bersifat hubungan perseorangan dengan Allah SWT (ibadah mabdah) dan hubungan perseorangan dengan manusia lain (ibadah ghair mabdah) secara berimbang, menyeluruh dan tetap. Salah satu tanda kemunculan pribadi-pribadi yang salih (baik) dalam

${ }^{14} \mathrm{Abi}$ Ishaq Ibrahim al-Syatibi, al-Muwafaqat $f i$ Ushul al-Abkam Jur. II, 177-79. 
pandangan Allah dan dalam pandangan manusia, apabila terciptanya pola keberagamaan yang komprehensif di kalangan umat Islam. ${ }^{15}$

Pengertian fiqh sosial atau disebut (alfigh al-ijtima'i) sejatinya adalah penyempurnaan bagi fiqh perseorangan (al-fiqh al-infiradi). Kajian fiqh sosial (al-figh al-ijtima i) lebih bertumpu pada kajian dari sisi hubungan antar sesama manusia, namun sebaliknya al-figh alinfiradi bertumpu pada sisi hubungan perseorangan dengan Allah (ibadah mabdah) dan hubungan manusia dengan manusia dalam bentuk perorangan (bayna al-fard wa'lfard). ${ }^{16}$ Melalui pendekatan bahasa ini, pemahaman yang berlatar belakang sosial atau figh akan dibangun dibangun atas dasar hubungan antar perseorangan atau kelompok dalam sosial kemasyarakatan. ${ }^{17}$

Gagasan fiqh sosial dapat dipahami sebagai politik hokum yang berbasis figh klasik dalam konteks perubahan social. Dalam upaya mengharmonisasi serta mengaplikasikan ajaran fiqh dengan perkembangan peristiwa yang muncul, maka maksud dari gagasan ini akan memuat segala dimensi fiqh, baik sudut pandang perseorangan (a1-infiradi) maupun sosial (al-ijtimai) sebagai wacana figh sosial. Seandainya fiqh sosial tidak dapat dipisahkan dari kedua sudut pandang cabang fiqh tersebut, namun keduanya justru saling memperkuat pola perilaku keberagaman masyarakat dalam ruang lingkup ibadah dan muamalah hingga berujung pada kesinambungan ajaran Islam yang bersifat humanis. ${ }^{18}$

\section{PROBLEMATIKA USHUL FIQH} DALAM MEWUJUDKAN FIQH SOSIAL

Bila fiqh adalah kumpulan dari hukum-

\footnotetext{
15Zubaedi, Membangun Fiqh..., 447

${ }^{16}$ Mahsun Fuad, Hukum Islam Indonesia Dari

Nalar Partisipatoris Hingga Emansipatoris, (Yogyakarta:LKiS, 2005), 109

${ }^{17}$ Zubaedi, Membangun Fiqh..., 447

${ }^{18}$ Ibid.
}

hukum yang berkaitan dengan perbuatan lahiriayah mukallaf yang digali dari dalaliltertentu, ushul figh adalah "serangkaian kaidah guna mengistimbatkan bukum syar'i yang bersifat amali atau praktis dari dalil - dalilnya yang terperinci".

Pada bagian terdahulu telah dikemukakan betapa fiqh sendiri berada dalam kejumudannya. Hal yang sama ternyata juga terjadi dalam ushul fiqh. Kata Amin Abdullah, bahwa kemunduran figh Islam dewasa ini kuat dugaan disebabkan oleh kurang relevannya ushul fiqh secara teoritik untuk memecahkan masalah kontemporer. Baik karya pada bidang ushul fiqh seperti; al-Risalah karya al-Syafi'i, kitab ushul aliran fuqaha dan mutakallimin semuanya bermuara pada penjabaran secara literalistic yang menggambarkan segala bentuk peristiwa hukum sesuai dengan teks ayat dan sangat minimnya memberikan komentar yang bersifat kontekstual ayat. ${ }^{19}$

Paradigma literalistic (al-tariqah allaf:iiyyah) tertuju langsung pada teks-teks nash Alquran dan Hadits untuk mengetahui petunjuk makna lafaz-lafaz yang dimaksudkannya. Membandingkan dengan pendapat Abid al-Jabiry, model pemikiran yang bertumpu pada kajian teks dan bahasa pada umumnya dikategorikan dalam corak pemikiran melalui pendekatan bayani, yang berbandung terbalik dengan pendekatan burbany dan irfani. ${ }^{20}$

Mayoritas fuqaha dalam catatan sejarahnya memang telah menggunakan pemikiran bayani sebagai landasan berpikirnya. Keilmuan yang berpijak pada pemikiran bayani termuat pada ilmu hukum Islam (figh), ilmu Kalam dan ilmu bahasa Arab serta seluk beluknya berlandaskan pada otoritas teks. Alquran dan Sunnah yang menjadi sumber

${ }^{19}$ Amin Abdullah, Mazhab Yogja,..., 118
${ }^{20}$ M.AminAbdullah, “Al-Ta'wil al-'Tlmi: Ke Arah Perubahan Paradigma Penafsiran Kitab Suci”, AlJamiah, (Yogyakarta: IAIN Sunan Kalijaga, 2001, Vol.39), 359-391. 
hukum Islam merupakan teks yang berbahasa Arab sehingga seliberal apa pun pemikiran hukum Islam tidak akan bisa sama sekali lepas dari teks. Karenanya pemikiran hukum Islam yang memiliki kecenderungan rasional-filosofis pada esensinya sama dengan pemikiran burbany, sebagai dasar analisis menemukan maksud teks sumber hukum Islam yaitu: Alquran dan as-Sunnah. Menurut al-Jabiri, bahwa kecenderungan pemikiran rasionalfilosofis dalam hukum Islam sama hal dengan dengan istilah ta'sis al-bayan 'ala al-burban (membangun disiplin ilmu bayani) dalam hukum Islam dengan dasar pijakan kerangka burhany. ${ }^{21}$

Untuk mencari jalan keluar untuk membongkar kejumudan fiqh selama ini, maka upaya pemahaman dan pemaknaan fiqh secara kontekstual menjadi sangat penting untuk dilakukan. Hingga, pendekatan etis dengan berorientasi esoterik (sufistik) yang bermuara pada rub tashri' atau maqasid al-shari'ah menjadi agenda penting untuk dilakukan dalam rangka mereformulasikan substansi dan tujuan fiqh.

Adalam menjadi tugas penting dan mendesak yang tidak bisa dihindari adalah melakukan pemahaman yang lebih kontekstual terhadap kitab-kitab figh yang telah ditulis para ulama pada abad III dan IV $\mathrm{H}$ agar tidak kehilangan perannya menjadi rambu bagi kehidupan masyarakat. Guna kepentingan ini, diperlukan keberanian dalam melakukan pembaharuan, sekurang-kurangnya reformulasi hukum dan tidak mentolerir adanya kevakuman hukum (dinyatakan mawquf), dengan dalih ulama terdahulu tidak membicarakannya.

Salah satu jalan lain yang mungkin dapat ditempuh adalah "menghidupkan" kembali tradisi berpikir metodologis (manhaji) dengan mengakomodasi berbagai manhaj yang telah dirumuskan para ulama mazhab Sunni, seperti qiyas, istihsan, maslahah mursalah, dan sadd al- zari'ah secara berkaitan. Pendekatan tersbut diperlukan untuk memperkaya tradisi bermazhab secara qauly dengan bermazhab secara manhajy. Dalam istilah lain diperlukan kelengkapan pendekatan secara tekstual yang sudah familiar di sebagian besar umat Islam dengan pendekatan kontekstual yang di dalamnya perlu mengakomodasikan dan mempertimbangkan dimensi kebutuhan riil dan kemaslahatan masyarakat.

Ushul fiqh dan Fiqh idealnya terus ber kembang dalam menghadapi tantangan realitas kehidupan modern. Menurut Hasan Turabi menyebut sejumlah alasan bagi perlunya pembaruan usul figh. Misalnya, menurutnya, produk-produk ushul figh dalam tradisi pemikiran figh klasik masih bersifat sangat abstrak dan berupa wacana teoritis yang tidak mampu melahirkan pemahaman komprehensif dan justru melahirkan perdebatan yang tak kunjung selesai. Turabi juga berkesimpulan, fiqh saat ini lebih berorientasi pada ijtihad dalam persoalan ibadah ritual dan masalah kekeluargaan, sementara persoalan hukum, ekonomi, hubungan luar negeri, dan sebagainya belum memiliki tempat yang semestinya dalam kajian fiqh. $^{22}$.

Konteks peristiwa sejarah masa lalu dengan masa sekarang dan masa yang akan datang tentu saja berbeda. Masyarakat modern mempunyai logika dan sikap yang jauh berbeda dengan apa yang dihadapi masyarakat Arab di zaman dulu. Kemungkinan juga letak geografis di mana Islam diturunkan dengan letak geografis Indonesia dan beberapa negara Asia lainnya memberikan inspirasi bagi lahirnya penafsiran baru terhadap dogma dan doktrin keagamaan.

Perbedaan yang signifikan dalam konteks sejarah inilah yang menyebabkan perlunya pembacaan yang bersifat distingtif 
antara maqasid al-Shariah dan syari'ah. Apa yang dihasilkan ulama pada masa lalu dianggap sebagai solusi bagi maslah kemanusiaan kontemporer. Sebagai akibatnya, pertama; syariat sebagai pengaturan tata nilai yang komprehensif menyangkut hubungan antara manusia dengan Tuhan (ibadah mahdab) dan hubungan manusia dengan manusia dan makhluk lainnya (mu'amalah), mengalami stagnasi (kebuntuan). Kedua, penampakan ke permukaan adalah sebagai wajah fiqh yang kaku, keras, dan ekstrim. Keilmuamn fiqh sebagai hasil kesimpulan sebuah hukum yang berasal dari Alquran dan Hadis pada akhirnya akan menjadi sangat teosentris, karena fiqh lebih dianggap sebagai otoritas pengetahuan daripada upaya mengamalkan doktrin keagamaan untuk menyelesaikan ketegangan yang terjadi dalam realitas sosial. Menurut Yusuf al-Qaradawi melihat kenyataan kebuntuan fiqh ini ditandai dengan sistematika figh yang dimulai dengan pembahasan ibadah. Menurut al-Qaradawi, karakteristik fiqh seperti ini telah membekukan cara pandang fiqh terhadap masalah-masalah sosial, ekonomi dan politik. $^{23}$

Oleh karena itu, al-Qaradawi mengajukan jalan pemikiran yang lain agar fiqh direformasikan menjadi figh prioritas (fiqh alawlawiyyat) dan fiqh realitas (figh al-waqi'), yaitu fiqh yang merupakan terobosan baru bagi problem kemanusiaan yang muncul di tengah masyarakat. Dengan hal tersebut, syariat diharapkan tidak lagi hanya bercorak teologis, yang hanya mengatur persoalan hubungan manusia dengan Allah SWT, melainkan semestinya bercorak humanistik yang mengatur persoalan manusia dengan sesama. Semakin terlihat bahwa mengkolaborasikan figh dengan disiplin kelimuan yang beragam merupakan langkah awal guna mendekonstruksi syariat agar menyentuh isuisu kewarganegaraan (figh al-muwatanah),

${ }^{23}$ Zubaedi, Membangun Fiqh..., 432 kesetaraan gender (figh al-mar'ah) dan ketatanegaraan (fiqh al-daulah), yang eksklusif, statis. Serta merubah diskriminasi syariat agar terbuka ruang pengamalannya secara inklusif, dinamis dan egalitarianistik.

Figh sosial (fiqh waqi') tampaknya baru bisa diwujudkan dengan memakai metodologi ushul figh kontekstual, metodologi dengan perspektif etis dengan bertujuan esoterik (sufistik) yang muaranya adalah rub tashri' atau maqasid al-shari'ah. Metode semacam ini tampaknya telah dilakukan oleh Qardhawi dalam menyusun pandangannya mengenai fiqh sosial ini.

\section{PERANAN PESANTREN DALAM MENJAGA DAN MENGEMBANGKAN ILMU USHUL FIQH}

Ilmu ushul figh termasuk ke dalam ilmu keislaman murni.Ilmu ushul figh ini tidak bisa dipisahkan dengan ilmu figh yang merupakan produk darinya. Menurut Zamahsori Zofir, naskah-naskah agama yang dipelajari atau dibaca oleh santri di pesantren adalah Nahwu, Sharaf, Fiqh, Ushul Fiqh, Hadis Tafsir, Tauhid, Tasauf, Tarekh, dan Balaghah. ${ }^{24}$

Dari segi metode pembelajaran di pondok pesantren biasanya menggunakan tiga metode.Pertama, pelajaran perseorangan atau kelompok kecil dalam studi dasar (sorongan). Kedua, Ceramah-ceramah yang ditujukan kepada kelompok-kelompok lebih besar, terdiri dari santri-santri lanjutan, disebut badongan (weton). Ketiga, acara seperti seminar untuk membahas masalah tingkat tinggi. ${ }^{25}$

Salah satu kelemahan pesantren terdapat pada rendahnya, visi, misa dan tujuan yang hendak dicapai oleh pesantren. Hanya sedikit pesantren yang mampu menyusun visi, misi, serta tujuannya dan melaksanakannya

24 Zamachsyari Zofir, Tradisi Pesantren, (Jakarta, 1992), 60

${ }^{25}$ Ibid. 
pada tahap-tahap perencanaan program kerja. Tidak dipunyinya rumusan dari tujuan tersebut karena terdapat kecenderungan menyerahkannya kepada kiyai atau secara bersama asistennya secara intuitif yang dicocokkan dengan pertumbuhan pesantren tersebut.

Di pihak lain, Azra mengatakan bahwa alam pesantren adalah alam yang mewarisi dan memelihara dan mewarisi keberlanjutan tradisi Islam yang dikembangkan oleh ulama dari wktu ke waktu, tanpa dibatasi oleh periode sejarah tertentu. ${ }^{26}$ Tradisi atau kebiasaan masyarakat Islam yang dikembangkan pada sejarah Islam, timbul di pesantren terutama pesantren tradisional yang pada umumnya memfokuskan kajiannnya terhadap bidang syari'ah serta tasawuf. Dengan tipologi semacam itu, pesantren tradisional sering diidentikkan dengan perbuatan bid'ah dan khurafat. Akan tetapi dalam sisi lain, pesantren tradisional memiliki kecenderungan untuk megang erat salafi. Ini menunjukkan bahwa paham yang dikembangkan oleh pesantren tradisional lebih menjurus kepada pemahaman Islam murni yang sebagaimana yang diamalkan oleh ulama pada awal yang terbebas dari praktek bidah dan khurafat. ${ }^{27}$

Dari visi Misi, metode pembelajaran, dan materi yang diajarkan dapat dipahami bahwa pesantren lebih banyak mempertahankan tradisi, termasuk tradisi keilmuan Islam murni, ketimbang mengembangkan keilmuan tersebut.Salah satu ciri dari tradisi keilmuan Islam klasik adalah tradisi teks, tidak tradisi pemikiran.Bahkan kadang-kadang teks-teks tersebut dihafalkan meskipun tidak diketahui maksud dan tujuan dari ilmu yang dihafal tersebut.

Sedikit berbeda dengan pesantren

${ }^{26}$ Azyumardi Azra, Pendidikan Islam, Tradisi dan Modernisasi Menuju Melinium Baru, (Jakarta, Logos, 1999), 107

${ }^{27}$ Ibid. tradisional (salaf), pada pesantren modern (khalaf) meskipun budaya hafalan cenderung tidak sekuat pada pesantren tradisional, tetapi tradisi teks masih tetap dipertahankan.Dapat dikatakan bahwa santri jarang bahkan tidak pernah diajak keluar dari teks-teks yang ada dengan jalan pepemikiranan ilmiah.Hal itu tidak hanya berlaku pada teks-teks ushul fiqh, bahkan juga pada teks-teks fiqh.

Dapat disimpulkan bahwa pesantren belum memainkan perannya dalam menjaga dan mengembangkan metodologi ushul fiqh.Kalaupun dikatakan ada, barangkali hanya sebatas mempertahankan teks, belum pada tingkat mengembangkan dan merumuskan metodoologi fiqh baru.

\section{KESIMPULAN}

Ushul figh sebenarnya cukup bisa memberikan respon terhadap realitas sosial.Hanya saja, bukan ushul fiqh yang bertumpu pada makna teks.Melainkan, dengan ushul figh baru yang lebih mengedepankan sisi pemikiran atau bertumpu kepada maqashid syari'ah, yakni makna atau tujuan yang ada di balik teks.

Ushul figh yang semacam ini yang kemudian juga mampu melahirkan fiqh kontekstual atau fiqh sosial yakni figh sebagai respon terhadap realitas sosial masyarakat.

Pesantren sendiri sebenarnya sangat potensial untuk menjaga dan mengambangkan ilmu ushul figh semacam ini.Sebaliknya, tidak berkutat dengan figh tradisional (klasik) begitu juga ushul fiqh tradisional yang hanya terpaku kepada makna-makna literal. 


\section{DAFTAR KEPUSTAKAAN}

Abdullah, Amin, Maz̧̧ab Yogja, Menggagas Paradigma Ushul Figh Kontemporer, Yogjakarta: Arruz Press, 2002.

"'Al-Ta’wil al-'Tlmi: Kearah Perubahan Paradigma Penafsiran Kitab Suci”, AlJami'ah, Yogyakarta: IAIN Sunan Kalijaga, 2001,Vol.39.

Abu Zaid, Farouk, Hukum Islam: Antara Tradisionalis dan Modernis, terj. Husein Husein Muhammad, Jakarta:P3M, 1986.

al-Jauziyyah, Ibn Qayyim, I'lam al-Munaqqi in 'an Rabb al-Alamin, Beirut: Dar al-Kutub al'Ilmiyyah, 1996, Juz 3.

al-Turabi, Hasan, Fiqih Demokratis, terj. Abdul Haris dan Zainul Am, Bandung: Arasy, 2003.

al-Syatibi, Abi Ishaq Ibrahim, al-Munvafaqat fi Ushul al-Abkam Juz. II.

Azra, Azyumardi, Pendidikan Islam, Tradisi dan Modernisasi Menuju Melinium Baru, Jakarta, Logos, 1999.

Busyro, Busyro, and Saiful Amin. "Kedudukan Bak Pencuci Kaki Sebelum Masuk Dan Keluar Tempat Berwudhuk Dalam Tinjauan Fiqh Ibadah." Alhurriyah: Jurnal Hukum Islam (Alburriyah Journal of Islamic Law) 3, no. 1 (June 22, 2018): 1. doi:10.30983/alhurriyah.v3i1.538.

Fuad, Mahsun, Hukum Islam Indonesia Dari Pemikiran Partisipatoris Hingga Emansipatoris, Yogyakarta:LKiS, 2005.

Hasan, Ahmad, The Early Development of Islamic Jurisprudence, Islamabad: Islamic Research Institute, 1970.

PP Muhammadiyah, "Manhaj Pengembangan Pemikiran Islam", http://www.geocities.com/tarjikh/Manhaj_tarjih/operasionalisasi.htm, diakses pada 26 Agustus 2018.

Rafiq, Ahmad, Fiqh Kontekstual, dari Normatif ke Pemaknaan Sosial, Yogyakarta: Pustaka Pelajar, 2004.

Zubaedi, Membangun Fiqh yang Berorientasi Sosial: Dialektika Fiqh dengan realitas Empirik Masyarakat, Al-Jami á, Vol.44 No.2, 2006M/1427H. 